\title{
Glucose variability and the risks of stroke, myocardial infarction, and all-cause mortality in individuals with diabetes: retrospective cohort study
}

Da Young Lee ${ }^{1 \dagger}$, Kyungdo Han²†, Sanghyun Park², Ji Hee Yu', Ji A. Seo ${ }^{1}$, Nam Hoon Kim', Hye Jin Yoo ${ }^{1}$, Sin Gon Kim ${ }^{1}$, Kyung Mook Choi ${ }^{1}$, Sei Hyun Baik ${ }^{1}$, Yong Gyu Park ${ }^{2^{*}}$ and Nan Hee Kim ${ }^{1,3^{*}}$

\begin{abstract}
Background: Previous research regarding long-term glucose variability over several years which is an emerging indicator of glycemic control in diabetes showed several limitations. We investigated whether variability in long-term fasting plasma glucose (FG) can predict the development of stroke, myocardial infarction (MI), and all-cause mortality in patients with diabetes.

Methods: This is a retrospective cohort study using the data provided by the Korean National Health Insurance Corporation. A total of 624,237 Koreans $\geq 20$ years old with diabetes who had undergone health examinations at least twice from 2005 to 2008 and simultaneously more than once from 2009 to 2010 (baseline) without previous histories of stroke or MI. As a parameter of variability of FG, variability independent of mean (VIM) was calculated using FG levels measured at least three times during the 5 years until the baseline. Study endpoints were incident stroke, MI, and all-cause mortality through December 31, 2017.

Results: During follow-up, 25,038 cases of stroke, 15,832 cases of MI, and 44,716 deaths were identified. As the quartile of FG VIM increased, the risk of clinical outcomes serially increased after adjustment for confounding factors including duration and medications of diabetes and the mean FG. Adjusted hazard ratios ( $95 \%$ confidence intervals) of FG VIM quartile 4 compared with quartile 1 were 1.20 (1.16-1.24), 1.20 (1.15-1.25), and 1.32 (1.29-1.36) for stroke, $\mathrm{MI}$ and all-cause mortality, respectively. The impact of FG variability was higher in the elderly and those with a longer duration of diabetes and lower FG levels.
\end{abstract}

Conclusions: In diabetes, long-term glucose variability showed a dose-response relationship with the risk of stroke, $\mathrm{Ml}$, and all-cause mortality in this nationwide observational study.

Keywords: Diabetes mellitus Glucose variability, Cardiovascular disease, Stroke, All-cause mortality, The Korean National Health Insurance Corporation

\footnotetext{
*Correspondence: ygpark@catholic.ac.kr; nhkendo@gmail.com

${ }^{\dagger}$ Da Young Lee and Kyungdo Han contributed equally to this article

${ }^{2}$ Department of Biostatics, College of Medicine, The Catholic University

of Korea, 222, Banpo-daero, Seocho-gu, Seoul 06591, Republic of Korea

${ }^{3}$ Division of Endocrinology and Metabolism, Department of Internal

Medicine, Korea University Ansan Hospital, Korea University College

of Medicine, Danwon-gu, Ansan-si, Gyeonggi-do 15355, Republic

of Korea

Full list of author information is available at the end of the article
}

(C) The Author(s) 2020. This article is licensed under a Creative Commons Attribution 4.0 International License, which permits use, sharing, adaptation, distribution and reproduction in any medium or format, as long as you give appropriate credit to the original author(s) and the source, provide a link to the Creative Commons licence, and indicate if changes were made. The images or other third party material in this article are included in the article's Creative Commons licence, unless indicated otherwise in a credit line to the material. If material is not included in the article's Creative Commons licence and your intended use is not permitted by statutory regulation or exceeds the permitted use, you will need to obtain permission directly from the copyright holder. To view a copy of this licence, visit http://creativeco mmons.org/licenses/by/4.0/. The Creative Commons Public Domain Dedication waiver (http://creativecommons.org/publicdomain/ zero/1.0/) applies to the data made available in this article, unless otherwise stated in a credit line to the data. 


\section{Background}

For individuals with diabetes, maintaining optimal blood glucose level is required to prevent complications and death [1]. However, as incident cardiovascular disease (CVD) and deaths associated with diabetes cannot be fully explained by increased HbA1c itself [2-4], more attention has been focused on non-traditional risk factors such as glucose variability (GV). Patients with diabetes with similar HbA1c values can have different daily glycemic profiles with variations in the duration and frequency of glycemic excursions [5]. Short-term GV usually means same-day or between-day glycemic oscillations and might be influenced by the individuals' diet, exercise, and treatment modality. Long-term GV represents the visit-to-visit variability in fasting glucose (FG) estimated over months to years; compliance with medication; and deterioration of insulin secretion and resistance, which can be important issues [6].

During the past decade, detrimental effects of GV on patients with diabetes have been proposed for various medical conditions [7-13]. GV could not only predict diabetic vascular complications [7, 14, 15], heart failure [9], and postoperative complications of aortic valve implantation [11], but also indicate poor prognosis for in-patients with acute lung diseases [8] and acute coronary syndrome [13]. Moreover, because GV could modify the correlation between time in range and estimated HbA1c, GV consideration was recommended when setting individualized goals for glycemic control [10].

Although there have been a few attempts to verify if GV can be a contributor to CVD or mortality $[6,7,15-$ 21], there is no consensus for patients with diabetes. Previous studies have yielded partial significance according to age, study group, or status of glycemic control [6, 7, 15-21]. In addition, they have several limitations such as small sample size and short-term follow-up periods.

In the present study, we used a nationwide populationbased database in Korea to investigate whether long-term variability in FG can predict the risk of stroke, myocardial infarction (MI), and all-cause mortality during a median 8 years of follow-up, to specify the population prone to the risk of higher $\mathrm{GV}$, and to compare it with single measurements of FG.

\section{Methods}

\section{Study design and subjects}

As shown in Fig. 1, we analyzed the data of patients with diabetes who had undergone health examinations provided by the National Health Insurance Corporation (NHIC) at least twice from 2005 to 2008 and simultaneously more than once between January 1,2009 , and December 31, 2010 (baseline exam). Among them, we excluded individuals aged $<20$ years and those with

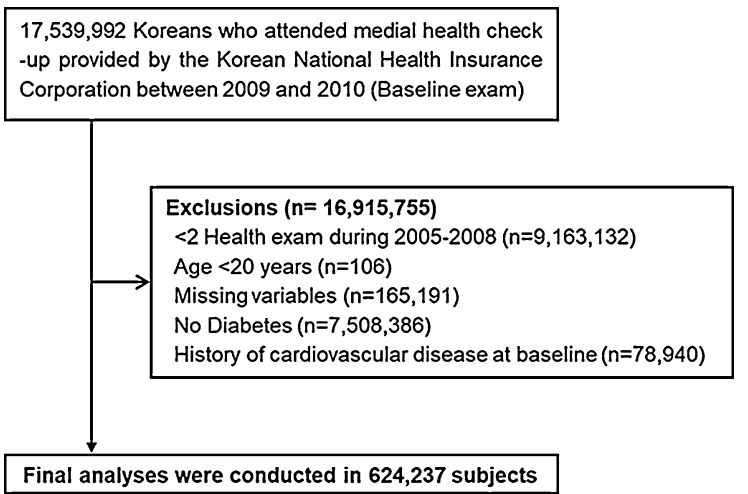

Fig. 1 Selection of study subjects

histories of stroke or MI, along with those missing data in the inclusion criteria. After those exclusions, 624,237 individuals were included in this study.

The NHIC is the single health insurance system operated by the Korean government and covers about $97 \%$ of the Korean population. It has an eligibility profile, health examination database (general health examinations and questionnaires on lifestyle), medical treatment information identified by the medical bills submitted by healthcare providers, and a medical care institution database [22, 23]. Enrollees are advised to undergo a standardized medical examination annually or biannually. The entire database of the NHIC is now open to all researchers.

The presence of diabetes was defined as at least one claim per year for the prescription of anti-diabetic medications under the International Classification of Diseases, Tenth Revision (ICD-10) codes E10-14 or a fasting plasma glucose level $\geq 7 \mathrm{~mm}$ ol/L. Type 1 diabetes (T1DM) was defined as ICD-10 code E10 with at least one prescription history of insulin. The remained subjects were referred to as type 2 diabetes (T2DM).

This study was approved by the official review committee in the NHIC and the Institutional Review Board of the Korea University Ansan Hospital (Institutional Review Board number 2019AS0158) and was carried out in accordance with the Helsinki Declaration of 1975.

\section{Definition of GV}

The variability independent of the mean (VIM) of FG was used as a primary variability parameter calculated from FG levels measured at least three times during the 5 years prior to the baseline (Fig. 2). The FG level at baseline was included in calculation of FG variability. Additionally, standard deviation (SD), coefficient of variation (CV, SD/mean), and average real variability (ARV) of FG 
during the same period were calculated using the following equation:

$$
\mathrm{VIM}=100 \times \frac{\mathrm{SD}}{\mathrm{mean}^{\beta}},
$$

where $\beta$ is derived by nonlinear regression analysis, based on the natural logarithm of SD over the natural logarithm of the mean [24].

$$
\mathrm{ARV}=\frac{1}{\mathrm{~N}-1} \sum_{\mathrm{k}=1}^{\mathrm{n}-1} \times\left|\mathrm{BP}_{\mathrm{K}+1}-\mathrm{BP}_{\mathrm{K}}\right|,
$$

where $\mathrm{k}$ ranges from 1 to $\mathrm{n}-1$, and $\mathrm{n}$ is the number of $\mathrm{FG}$ measurements.

\section{Study outcomes}

Incidences of stroke, MI, or death until December 31, 2017, were the endpoints of this study. Stroke was defined as the recording of ICD-10 codes I63 or I64 during admission with simultaneous claims for brain $\mathrm{CT}$ or MRI. MI was diagnosed by the recording of ICD-10 codes I21 or I22 with hospitalization. Deceased cases were identified based on nationwide death certificate data from the Korea National Statistical Office regardless of a previous diagnosis of stroke or MI. The time interval between the baseline examination and the date of study outcome or December 31, 2017 is defined as the followup period.

\section{Anthropometric and laboratory measurements}

We used data from questionnaires regarding demographic characteristics, lifestyle, medical history, and medications during the medical examination. Alcohol consumption habit was divided into near abstinence, moderate $(<30 \mathrm{~g} /$ day $)$, or severe ( $\geq 30 \mathrm{~g} /$ day). Smoking history was categorized as never, ex-, and current smokers. Doing regular exercise was defined $>20 \mathrm{~min}$ of vigorous-intensity or $>30$ min of moderate-intensity exercise at least once per week [25]. Body mass index (BMI) was estimated by weight in kilograms divided by the square of height in meters. Waist circumference was checked at the middle point between the iliac crest and the rib cage.

The presence of hypertension was defined as systolic blood pressure $(\mathrm{BP}) \geq 140 \mathrm{mmHg}$, diastolic $\mathrm{BP} \geq 90 \mathrm{mmHg}$, or the presence of at least one

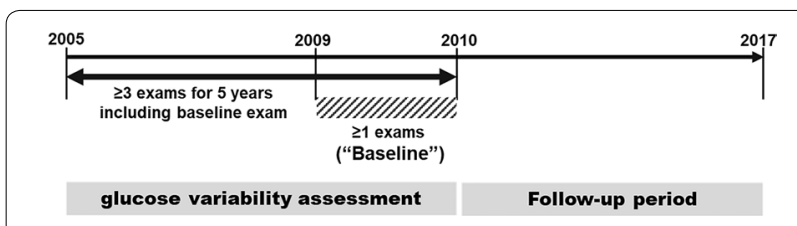

Fig. 2 Assessment of glucose variability and follow-up period prescription of anti-hypertensive medications under ICD-10 codes I10-I15 per year. The presence of malignancy was determined by registration in the Korea Central Cancer Registry under the International Classification of Diseases, ICD-10 C00-C96 before baseline examination. Low-income status was defined by the lowest $20 \%$.

Venous blood samples were drawn in the morning after an overnight fast of at least 8 hours to measure the levels of plasma glucose, total cholesterol, triglycerides, highdensity lipoprotein cholesterol, low-density lipoprotein cholesterol (LDL-C), and creatinine.

Dyslipidemia was defined as total cholesterol level $\geq 6.21 \mathrm{mmol} / \mathrm{L}$ or the presence of at least one claim per year for the prescription of anti-hyperlipidemic drugs under ICD-10 code E78. The estimated glomerular filtration rate (eGFR) was estimated by the Modification of Diet in Renal Disease formula [26], and eGFR $<60 \mathrm{~mL} /$ $\min / 1.73 \mathrm{~m}^{2}$ was classified as chronic kidney disease (CKD) [27]. The number of oral anti-diabetic medication among metformin, sulfonylurea, meglitinide, thiazolidinedione, inhibitors of dipeptidyl peptidase 4 (DPP-4 inhibitors), and acarbose taken in the 12 months prior to baseline was identified. The history of heart disease was identified by self-report.

Quality control of the laboratory tests was conducted in accordance with the Korean Association of Laboratory Quality Control.

\section{Statistical analysis}

Data are presented as mean \pm SD, geometric mean $(95 \%$ confidence intervals [CIs]), or number (\%). The baseline characteristics were compared using Chi square tests for categorical variables and analysis of variance for continuous variables after dividing the subjects according to the FG VIM quartile. Triglyceride levels were log-transformed for analysis.

To assess the risks of stroke, MI, and all-cause mortality, we conducted multivariate-adjusted Cox proportional hazards analyses according to FG VIM quartiles and deciles, using quartile 1 or decile 1 as the reference group.

We adjusted for confounders at baseline using two models. Model 1 was adjusted for age, sex, BMI, alcohol drinking, smoking, regular exercise, presence of hypertension and dyslipidemia, CKD, and low-income status. Model 2 is the same as model 1, plus further adjustment for duration of diabetes over 5 years, the number of classes of oral anti-diabetic medication, insulin prescription history taken in the 12 months prior to baseline, and mean FG during the 5 years preceding the baseline exam.

We conducted several subgroup analyses to evaluate the effects of age; sex; BMI; smoking; income status; 
presence of hypertension, dyslipidemia, and malignancy; duration of diabetes; baseline FG level; subtype of diabetes; and anti-diabetic medication. The hazard ratios (HRs) and 95\% CIs for stroke, MI, and all-cause death in FG VIM quartile 4 versus quartiles $1-3$, with adjustments for confounders, were estimated.

To compare with the predictive value of a single FG level, we performed the above-mentioned Cox analysis according to baseline FG level, with FG levels of 100$119 \mathrm{mg} / \mathrm{dL}$ being the reference group. The mean of FG was excluded as a confounder in this analysis. Additionally, we repeated this analysis after stratifying the subjects according to prescription history of anti-diabetic medication.

We checked a variable inflation factor for all covariates of less than 2.0 and found no relevant multicollinearity in covariates. SAS version 9.3 (SAS Institute Inc., Cary, NC, USA) was used for statistical analysis. A $p$ value of $<0.05$ was considered to be statistically significant.

\section{Results}

FG VIM quartile 4 had more males and current smokers and showed higher FG and triglyceride levels compared with quartile 1 (Table 1). On the other hand, this group was younger, had a lower BP and LDL-C level, and had lower proportions of hypertension, dyslipidemia, and heart disease versus quartile 1 . About $46 \%$ of the highest VIM quartile was not treated with any anti-hyperglycemic agents. However, a higher proportion of them was treated with insulin for the preceding 12 months than other tertiles.

During the median (interquartile range) follow-up period of 8.0 (7.3-8.4) years, 25,038 cases of stroke, 15,832 cases of MI, and 44,716 cases of death were identified. As shown in Table 2, the HRs for stroke, MI, and allcause mortality serially increased as the FG VIM quartile increased. Subjects in FG VIM quartile 4 had a $20 \%$ higher risk for stroke and MI, and a 32\% higher risk for all-cause mortality, versus those in quartile 1 , even after adjustment for several risk factors and mean FG. We also tested the following GV calculation methods: SD, CV, and ARV. A similar relationship was obtained in FG SD, $\mathrm{CV}$, and ARV quartiles instead of VIM (Additional file 1: Table S1).

When we divided individuals into FG VIM deciles, the risks of stroke, MI, and all-cause death showed a positive dose-response association with the FG VIM decile (Fig. 3 and Additional file 1: Table S2).

In the subgroup analyses, FG VIM quartile 4 showed a consistently increased risk for all-cause mortality (Tables 3 and 4) except in young individuals aged 20-39. A similar finding was observed for stroke and MI, with exceptions in younger individuals and those with malignancy, shorter diabetes duration, baseline $\mathrm{FG} \geq 126 \mathrm{mg} / \mathrm{dL}$, T1DM, and treatment with thiazolidinedione and insulin.

On the other hand, the relationship between FG status and the risk of clinical outcomes showed a U-shaped association (Fig. 4 and Additional file 1: Table S3). Compared to individuals whose FG levels were in the range $100-119 \mathrm{mg} / \mathrm{dL}$, those with FG $<100 \mathrm{mg} / \mathrm{dL}$ or $\geq 160 \mathrm{mg} /$ dL had significantly higher HRs. This relationship was consistent after dividing the subjects by prescription of anti-diabetic medications (Additional file 1: Table S4).

\section{Discussion}

This nationwide population-based study in diabetes revealed that long-term GV for 5 years predicted future development of stroke, MI, and all-cause death, independent of anti-diabetic medication, metabolic risk factors, and mean fasting glucose. This association showed a linear fashion, compared to the U-shaped association between FG and outcomes. In the subgroup analysis, the impact of GV was higher in the elderly and those with a longer duration of diabetes and lower FG levels.

\section{Long-term glucose variability and clinical outcomes}

Several medium-sized cohort studies have reported the impact of long-term GV $[6,15,17-21]$. Variability in FG is an independent predictor of all-cause mortality, and the highest tertile group in 1400 type 2 diabetes patients included in the VERONA study had a $67 \%$ higher risk $[17,21]$. In the sub-analysis of the Action in Diabetes and Vascular Disease: Preterax and Diamicron MR Controlled Evaluation (ADVANCE) trial, variability in FG was associated with an increased risk of death from cardiovascular causes, nonfatal MI, or nonfatal stroke [15]. Furthermore, GV might reflect better the impact of glycemic control on diabetic complications than HbA1c, or at least, GV can complement the power of HbA1c in risk prediction $[7,14,15]$. In the ADVANCE trial, HRs (95\% CIs) estimated for each 10-percentile point increase in SD of FG and HbA1c were $1.12(1.08-1.16)$ and 1.05 (1.01-1.09), respectively [15].

However, these studies have limitations such as short follow-up period [15] and a relatively small population size, and the impact of GV was only shown in some subgroups, but not the entire population [18]. In the present study, we computed long-term GV over 5 years and assessed risk for a median of 8 years of follow-up. In addition, this dataset includes almost all Korean diabetic patients. In this respect, the worst outcome in the highest GV quartile even after adjustment for mean FG provides a clear indication that GV can be considered as a new risk factor for stroke, MI, and all-cause mortality. 
Table 1 Baseline characteristics of the study subjects according to quartiles of fasting glucose variability

\begin{tabular}{|c|c|c|c|c|c|}
\hline Characteristics & VIM Q1 $(n=156061)$ & VIM Q2 $(n=156058)$ & VIM Q3 $(n=156060)$ & VIM Q4 $(n=156058)$ & $P$ value \\
\hline Age (years) & $58.6 \pm 10.6$ & $57.4 \pm 11.0$ & $56.5 \pm 11.7$ & $54.7 \pm 13.1$ & $<0.001$ \\
\hline Sex, male (\%) & $98563(63.2)$ & $101947(65.3)$ & $103675(66.4)$ & $106869(68.5)$ & $<0.001$ \\
\hline $\mathrm{BMI}\left(\mathrm{kg} / \mathrm{m}^{2}\right)$ & $24.9 \pm 3.0$ & $25.0 \pm 3.1$ & $25.1 \pm 3.2$ & $24.9 \pm 3.4$ & $<0.001$ \\
\hline WC $(\mathrm{cm})$ & $85.2 \pm 8.0$ & $85.5 \pm 8.0$ & $85.6 \pm 8.2$ & $85.1 \pm 8.6$ & $<0.001$ \\
\hline Systolic BP (mmHg) & $128.6 \pm 15.2$ & $128.8 \pm 15.0$ & $128.6 \pm 15.0$ & $127.8 \pm 15.0$ & $<0.001$ \\
\hline Fasting glucose (mg/dL) & $143.8 \pm 40.5$ & $142.0 \pm 38.0$ & $142.4 \pm 41.1$ & $146.2 \pm 50.7$ & $<0.001$ \\
\hline Triglyceride (mg/dL) & $141.9(141.5-142.3)$ & $146.7(146.3-147.1)$ & $149.7(149.3-150.1)$ & $148.8(148.3-149.2)$ & $<0.001$ \\
\hline $\mathrm{HDL}-\mathrm{C}(\mathrm{mg} / \mathrm{dL})$ & $52.0 \pm 21.8$ & $51.8 \pm 21.2$ & $51.6 \pm 21.1$ & $51.7 \pm 20.9$ & $<0.001$ \\
\hline LDL-C (mg/dL) & $111.6 \pm 45.0$ & $111.9 \pm 44.4$ & $111.4 \pm 44.7$ & $110.3 \pm 46.5$ & $<0.001$ \\
\hline GLU_SD (mg/dL) & $12.4 \pm 9.8$ & $22.7 \pm 14.1$ & $32.3 \pm 18.7$ & $47.1 \pm 25.3$ & $<0.001$ \\
\hline GLU_CV (\%) & $8.1 \pm 4.0$ & $15.5 \pm 5.0$ & $22.9 \pm 6.9$ & $35.5 \pm 11.9$ & $<0.001$ \\
\hline GLU_VIM (\%) & $4.1 \pm 1.8$ & $9.6 \pm 1.3$ & $14.6 \pm 1.7$ & $24.3 \pm 5.7$ & $<0.001$ \\
\hline GLU_ARV $(\mathrm{mg} / \mathrm{dL})$ & $15.2 \pm 12.9$ & $27.0 \pm 18.8$ & $37.8 \pm 25.2$ & $52.4 \pm 33.7$ & $<0.001$ \\
\hline Current smoker (\%) & $33185(21.3)$ & $37301(23.9)$ & $42135(27)$ & $48736(31.2)$ & $<0.001$ \\
\hline Heavy drinking (\%) & $14997(9.6)$ & $15563(10.0)$ & $15755(10.1)$ & $14992(9.6)$ & $<0.001$ \\
\hline Regular exercise (\%) & $40718(26.0)$ & $38546(24.7)$ & $36142(23.2)$ & $32955(21.1)$ & $<0.001$ \\
\hline \multicolumn{6}{|l|}{ Comorbidities } \\
\hline Hypertension (\%) & $89659(57.5)$ & $87808(56.3)$ & $84796(54.3)$ & $78148(50.1)$ & $<0.001$ \\
\hline Dyslipidemia (\%) & $60077(38.5)$ & $58915(37.8)$ & $56500(36.2)$ & $50461(32.3)$ & $<0.001$ \\
\hline CKD (\%) & $15740(10.1)$ & $15962(10.2)$ & $16598(10.7)$ & $17320(11.1)$ & $<0.001$ \\
\hline Heart disease (\%) & $6265(4.6)$ & $5786(4.3)$ & $5189(4.0)$ & $4564(3.7)$ & $<0.001$ \\
\hline Any malignancy (\%) & $4125(2.6)$ & $3930(2.5)$ & $3772(2.4)$ & $3892(2.5)$ & 0.001 \\
\hline Income (lower 20\%, \%) & $34507(22.1)$ & $35412(22.7)$ & $37482(24.0)$ & $39595(25.4)$ & $<0.001$ \\
\hline \multicolumn{6}{|l|}{ Antidiabetic medication } \\
\hline Metformin & $84747(54.3)$ & $77947(50.0)$ & $72119(46.2)$ & $62185(39.9)$ & $<0.001$ \\
\hline Sulfonylurea & $81607(52.3)$ & $77767(49.8)$ & $74710(47.9)$ & $66155(42.4)$ & $<0.001$ \\
\hline Meglitinide & $4246(2.7)$ & $4050(2.6)$ & $3850(2.5)$ & $3785(2.4)$ & $<0.001$ \\
\hline Thiazolidinedione & $14054(9.0)$ & $13354(8.6)$ & $12355(7.9)$ & $10933(7.0)$ & $<0.001$ \\
\hline DPP-4 inhibitor & $13802(8.8)$ & $12730(8.2)$ & $11766(7.5)$ & $9535(6.1)$ & $<0.001$ \\
\hline a-Glucosidase inhibitor & $21803(14.0)$ & $20564(13.2)$ & $20055(12.9)$ & $18458(11.8)$ & $<0.001$ \\
\hline Insulin & $10064(6.5)$ & $9936(6.4)$ & $10655(6.8)$ & $13320(8.5)$ & $<0.001$ \\
\hline Number of oral anti-diabetic medications & & & & & $<0.001$ \\
\hline 0 & $42298(27.1)$ & $51240(32.8)$ & $58967(37.8)$ & $72375(46.4)$ & \\
\hline 1 & $38976(25.0)$ & $33797(21.7)$ & $29285(18.8)$ & $23217(14.9)$ & \\
\hline 2 & $48766(31.3)$ & $45997(29.5)$ & $43216(27.7)$ & $38441(24.6)$ & \\
\hline$\geq 3$ & $26021(16.7)$ & $25024(16.0)$ & $24592(15.8)$ & $22025(14.1)$ & \\
\hline Duration of diabetes $\geq 5$ years $(\%)$ & $62489(40.0)$ & $55604(35.6)$ & $50193(32.2)$ & $43641(28.0)$ & $<0.001$ \\
\hline Type 1 diabetes (\%) & $3104(2.0)$ & $3214(2.1)$ & $3745(2.4)$ & $5548(3.6)$ & $<0.001$ \\
\hline Number of exams & & & & & $<0.001$ \\
\hline 3 & $126421(81.0)$ & $113451(72.7)$ & $108293(69.4)$ & $104468(66.9)$ & \\
\hline 4 & $14692(9.4)$ & $19227(12.3)$ & $21858(14.0)$ & 24324 (15.6) & \\
\hline 5 & 14948 (9.6) & $23380(15.0)$ & 25909 (16.6) & $27266(17.5)$ & \\
\hline $\begin{array}{l}\text { Time interval between adjacent exams } \\
\text { (years) }\end{array}$ & $1.8 \pm 0.3$ & $1.7 \pm 0.3$ & $1.7 \pm 0.3$ & $1.7 \pm 0.3$ & $<0.001$ \\
\hline
\end{tabular}

Q1:0-7.4; Q2:7.4-11.9; Q3:11.9-17.8; Q4:17.8-87.7. Data are presented as mean \pm standard deviation, geometric mean (95\% confidence interval), or number (\%). Oneway analysis of variance and Chi squared tests were used to compare the characteristics of the study subjects at baseline. Post-hoc multiple comparison analysis was performed with Bonferroni correction, and triglyceride levels were log-transformed for analysis. ARV, average real variability; BMI, body mass index; BP, blood pressure; CKD, chronic kidney disease; CV, coefficient of variation; HDL-C, high-density lipoprotein-cholesterol; LDL-C, low-density lipoprotein-cholesterol; SD, standard deviation; VIM, variability independent of mean; WC, waist circumference 
Table 2 Hazard ratios (HRs) and 95\% confidence intervals (Cls) for the incidence of stroke, myocardial infarction, and allcause mortality by quartile of fasting glucose variability

\begin{tabular}{|c|c|c|c|c|c|c|}
\hline & \multirow[t]{2}{*}{ Events (n) } & \multirow[t]{2}{*}{$\begin{array}{l}\text { Follow-up duration } \\
\text { (person-years) }\end{array}$} & \multirow[t]{2}{*}{$\begin{array}{l}\text { Incidence rate (per } \\
1000 \text { person-years) }\end{array}$} & \multirow{2}{*}{$\begin{array}{l}\text { Age- and sex- } \\
\text { Adjusted HR ( } 95 \% \\
\text { CI) }\end{array}$} & \multicolumn{2}{|c|}{$\begin{array}{l}\text { Multivariate-adjusted HR (95\% } \\
\text { Cl) }\end{array}$} \\
\hline & & & & & Model 1 & Model 2 \\
\hline \multicolumn{7}{|l|}{ Stroke } \\
\hline VIM Q1 ( $n=156061)$ & 6350 & 1185704.0 & 5.36 & 1 (Ref.) & 1 (Ref.) & 1 (Ref.) \\
\hline VIM Q2 ( $n=156058)$ & 6162 & 1191326.6 & 5.17 & $1.03(0.99-1.07)$ & $1.03(0.99-1.06)$ & $1.06(1.02-1.09)$ \\
\hline VIM Q3 $(n=156060)$ & 6214 & 1193013.0 & 5.21 & $1.08(1.04-1.12)$ & $1.05(1.02-1.09)$ & $1.10(1.06-1.14)$ \\
\hline VIM Q4 ( $n=156058)$ & 6312 & 1191670.8 & 5.30 & $1.17(1.13-1.21)$ & $1.10(1.07-1.14)$ & $1.20(1.16-1.24)$ \\
\hline$P$ for trend & & & & $<0.001$ & $<0.001$ & $<0.001$ \\
\hline \multicolumn{7}{|l|}{ Myocardial infarction } \\
\hline VIM Q1 ( $n=156061)$ & 3859 & 1194006.5 & 3.23 & 1 (Ref.) & 1 (Ref.) & 1 (Ref.) \\
\hline VIM Q2 (n=156058) & 3899 & 1199121.6 & 3.25 & $1.06(1.01-1.11)$ & $1.05(1.00-1.10)$ & $1.07(1.02-1.12)$ \\
\hline VIM Q3 ( $n=156060)$ & 3978 & 1200620.1 & 3.31 & $1.11(1.07-1.16)$ & $1.09(1.04-1.13)$ & $1.12(1.07-1.17)$ \\
\hline VIM Q4 ( $n=156058)$ & 4096 & 1199009.4 & 3.42 & $1.21(1.16-1.27)$ & $1.14(1.09-1.20)$ & $1.20(1.15-1.25)$ \\
\hline$P$ for trend & & & & $<0.001$ & $<0.001$ & $<0.001$ \\
\hline \multicolumn{7}{|l|}{ All-cause mortality } \\
\hline VIM Q1 $(n=156061)$ & 10506 & 1205853.5 & 8.71 & 1 (Ref.) & 1 (Ref.) & 1 (Ref.) \\
\hline VIM Q2 ( $=156058)$ & 10608 & 1211059.8 & 8.76 & $1.09(1.06-1.119)$ & $1.08(1.05-1.11)$ & $1.10(1.07-1.13)$ \\
\hline VIM Q3 ( $n=156060)$ & 11181 & 1212864.1 & 9.22 & $1.19(1.16-1.22)$ & $1.15(1.12-1.18)$ & $1.17(1.14-1.20)$ \\
\hline VIM Q4 (n=156058) & 12421 & 1211473.9 & 10.25 & $1.40(1.36-1.44)$ & $1.29(1.26-1.33)$ & $1.32(1.29-1.36)$ \\
\hline$P$ for trend & & & & $<0.001$ & $<0.001$ & $<0.001$ \\
\hline
\end{tabular}

Q1:0-7.4; Q2:7.4-11.9; Q3:11.9-17.8; Q4:17.8-87.7. Model 1 is adjusted for age, sex, body mass index, alcohol drinking, smoking, regular exercise, presence of hypertension, dyslipidemia, chronic kidney disease, and lower $20 \%$ income. Model 2 is the same as model 1, plus further adjustment for duration of diabetes over 5 years, the number of classes of oral anti-diabetic medication taken in the 12 months prior to baseline, presence of prescription history of insulin, and mean of fasting glucose. VIM, variability independent of mean

\section{Interpretation of the impact of glucose variability}

A few mechanisms might be involved in the relationship between FG variability and clinical outcomes. Transient high glucose spikes have been shown to impair endothelial function [28, 29], increase oxidative stress more than sustained chronic hyperglycemia [30, 31], and induce $\beta$-cell dysfunction [12]. Furthermore, higher GV was strongly associated with increased lipid level and decreased fibrous content with a larger plaque burden [32].

In subgroup analysis of this study, the impact of GV was greater in the elderly and those with a longer duration of diabetes and FG level $<126 \mathrm{mg} / \mathrm{dL}$. These findings were partially in accordance with previous publications $[18,20]$. In the Verona Diabetes Study, the positive association between GV and mortality risk was confined to patients older than 65 years [18]. The elderly are known to be more susceptible to oxidative stress than younger individuals because their defense mechanisms are less efficient [19]. The limited significance seen in current smokers could be explained by the higher proportion of young subjects in the current smoker group. In the same notion, patients with a longer diabetes duration and lower FG might reflect a population that is more vulnerable to GV. It is interesting that contrary to other studies $[15,19,20], G V$ had a greater impact among lower FG patients than in higher FG patients, which may be due to an ethnic difference, but the reason is difficult to ascertain from this study. As we also showed that lower FG level was significantly associated with more CVD and death events, the higher GV in the lower FG group augmented the risk for future CVD and death, indicating the target population for reducing these outcomes.

In addition to this pathophysiologic interpretation, elevated GV might be an indicator of irregular compliance to therapy, comorbidity, poor health, or diabetic complications resulting in the increase of mortality [17]. However, contrary to other studies [14, 17, 20], our study population with higher GV had a shorter duration of diabetes, had fewer comorbidities, and about half of them were not treated with anti-diabetic medication. Although there was a greater proportion of insulin users, the contribution of insulin users to the outcome was small since less than $10 \%$ of the study population was treated with insulin. We speculate that, compared to other hospitalbased studies, this study included more low-risk diabetic 


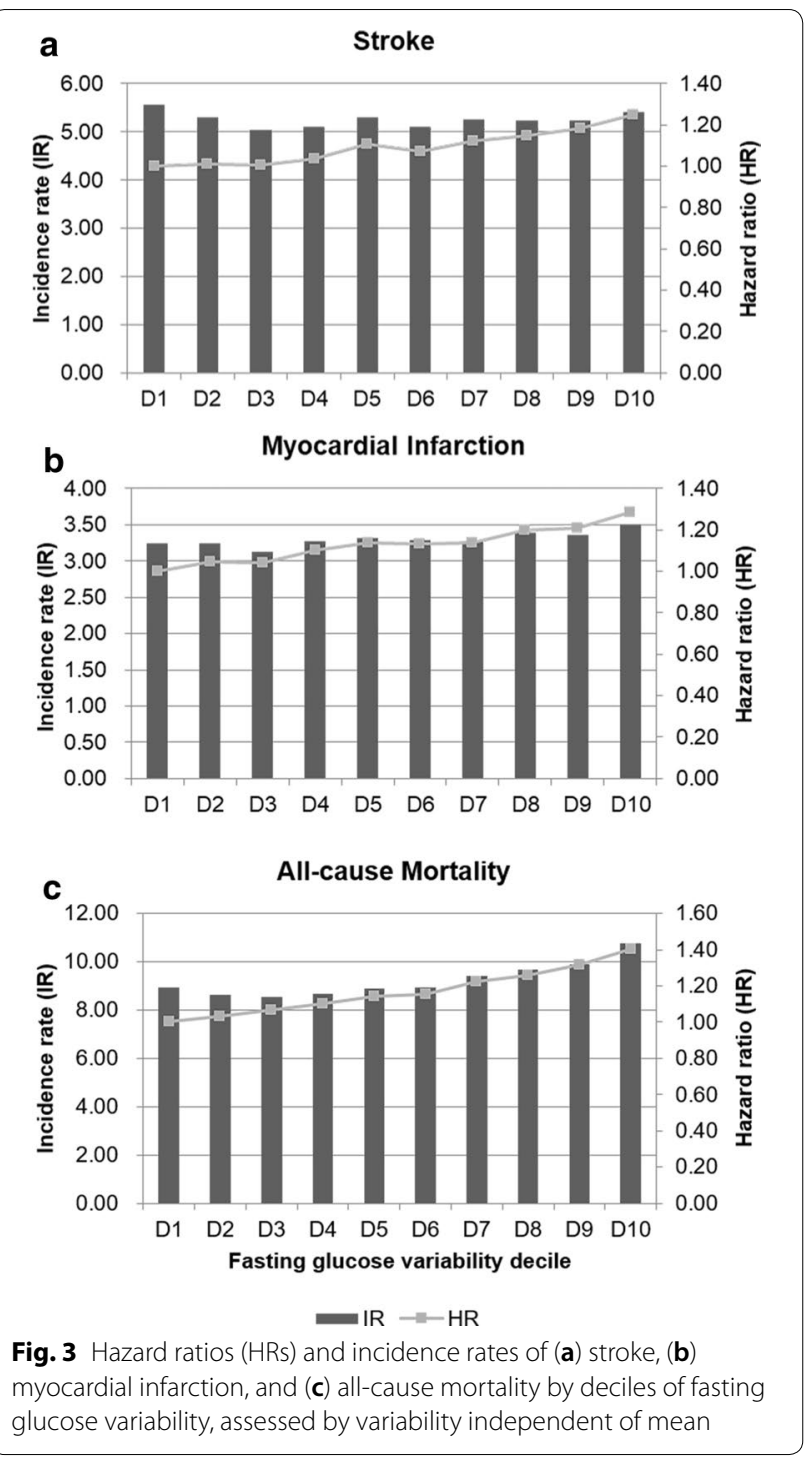

patients since diagnosis of diabetes was based on not only health insurance claims data, but also general health screening exams, which resulted in detection of undiagnosed mild diabetic cases. Therefore, we can evaluate the impact of GV itself, rather than combined poor health status and comorbidities as in other studies.
In subgroup analysis according to anti-diabetic medications, interaction analysis did not find any significance, contrary to previous studies which showed sulfonylurea increases glucose fluctuation and risk of hypoglycemia [33], and DPP-4 inhibitors and the novel insulin analogue degludec reduced GV [34-36]. Given that actual drug exposure could not be determined because of the retrospective study design, a future welldesigned, randomized controlled trial is expected to resolve this concern.

\section{Assessment of glycemic variability}

There are no standard indices for quantification of longterm glycemic variability [37], so each value has distinct characteristics. The SD reflects dispersion of measurements around the mean and is sensitive to low sampling frequency, while $\mathrm{CV}$ is a standardized variation providing direct comparison among study groups. The ARV index, which averages the absolute differences between successive measurements, might be a reliable index for time series variability $[38,39]$. However, SD, CV, and ASV are partially dependent on the mean and its changes over time, and this may not be resolved even if adjusted for mean value [40]. On the other hand, VIM is a measure of variability designed not to correlate with mean level [24, 41] but is sample-specific [42, 43]. Therefore, we used VIM as the main measurement of FG variability, and similar results to other estimates of glycemic variation support the robustness of our study (Additional file 1: Table S1).

\section{Limitations of this study}

This is the first large-scale epidemiologic study demonstrating the impact of long-term variability in FG on CVD outcomes separately and all-cause death with a longterm follow-up of 8.0 (7.3-8.4) years. However, we are aware of several limitations of this study. First, given that $\mathrm{HbA1c}$ or postprandial glucose level was not measured in this study, incident diabetes might be underestimated. To enhance the accuracy of diabetes diagnosis, we combined 
Table 3 Subgroup analysis according to clinically relevant factors in quartile 4 versus fasting glucose variability of quartiles 1-3

\begin{tabular}{|c|c|c|c|c|c|c|}
\hline & \multicolumn{2}{|l|}{ Stroke } & \multicolumn{2}{|c|}{ Myocardial infarction } & \multicolumn{2}{|c|}{ All-cause mortality } \\
\hline & IR per 1000 & $\mathrm{HR}(95 \% \mathrm{Cl})$ & IR per 1000 & $\mathrm{HR}(95 \% \mathrm{Cl})$ & IR per 1000 & $\mathrm{HR}(95 \% \mathrm{Cl})$ \\
\hline \multicolumn{7}{|l|}{ Age (years) } \\
\hline $20-39(n=51687)$ & 0.56 & $0.78(0.59-1.03)$ & 0.93 & $0.89(0.72-1.09)$ & 1.14 & $1.01(0.84-1.22)$ \\
\hline $40-64(n=413136)$ & 3.43 & $1.04(0.99-1.09)$ & 2.50 & $1.07(1.01-1.12)$ & 4.82 & $1.17(1.13-1.21)$ \\
\hline$\geq 65(n=159414)$ & 12.08 & $1.13(1.09-1.18)$ & 6.35 & $1.12(1.07-1.18)$ & 24.15 & $1.18(1.15-1.21)$ \\
\hline$P$ for interaction & & 0.001 & & 0.056 & & 0.102 \\
\hline \multicolumn{7}{|l|}{ Sex } \\
\hline Male $(n=411054)$ & 5.07 & $1.05(1.01-1.09)$ & 3.29 & $1.06(1.01-1.11)$ & 10.15 & $1.17(1.14-1.20)$ \\
\hline Female $(n=213183)$ & 5.62 & $1.13(1.07-1.18)$ & 3.33 & $1.13(1.07-1.21)$ & 7.49 & $1.19(1.14-1.24)$ \\
\hline$P$ for interaction & & 0.028 & & 0.071 & & 0.387 \\
\hline \multicolumn{7}{|l|}{ BMI } \\
\hline$<25 \mathrm{~kg} / \mathrm{m}^{2}(\mathrm{n}=331714)$ & 5.66 & $1.10(1.06-1.14)$ & 3.44 & $1.08(1.03-1.13)$ & 11.31 & $1.19(1.16-1.22)$ \\
\hline$\geq 25 \mathrm{~kg} / \mathrm{m}^{2}(\mathrm{n}=292523)$ & 4.81 & $1.05(1.01-1.10)$ & 3.15 & $1.10(1.04-1.16)$ & 6.91 & $1.14(1.10-1.18)$ \\
\hline$P$ for interaction & & 0.117 & & 0.477 & & 0.020 \\
\hline \multicolumn{7}{|l|}{ Current smoking } \\
\hline No $(n=462880)$ & 5.33 & $1.13(1.09-1.17)$ & 3.23 & $1.12(1.07-1.17)$ & 9.11 & $1.19(1.16-1.22)$ \\
\hline Yes $(n=161357)$ & 5.06 & $0.94(0.89-0.99)$ & 3.53 & $1.01(0.95-1.08)$ & 9.59 & $1.15(1.10-1.19)$ \\
\hline$P$ for interaction & & $<0.001$ & & 0.026 & & 0.089 \\
\hline \multicolumn{7}{|l|}{ Hypertension } \\
\hline No $(n=283826)$ & 3.35 & $1.02(0.97-1.08)$ & 2.38 & $1.01(0.95-1.08)$ & 6.50 & $1.17(1.13-1.21)$ \\
\hline Yes $(n=340411)$ & 6.89 & $1.11(1.07-1.14)$ & 4.09 & $1.13(1.09-1.19)$ & 11.55 & $1.19(1.16-1.22)$ \\
\hline$P$ for interaction & & 0.011 & & 0.001 & & 0.845 \\
\hline \multicolumn{7}{|l|}{ Dyslipidemia } \\
\hline No $(n=398284)$ & 5.24 & $1.05(1.01-1.09)$ & 3.09 & $1.09(1.04-1.14)$ & 9.99 & $1.17(1.15-1.20)$ \\
\hline Yes $(n=225953)$ & 5.29 & $1.13(1.07-1.18)$ & 3.68 & $1.10(1.04-1.16)$ & 7.93 & $1.19(1.15-1.24)$ \\
\hline$P$ for interaction & & 0.007 & & 0.397 & & 0.476 \\
\hline \multicolumn{7}{|l|}{ Malignancy } \\
\hline No $(n=608518)$ & 5.25 & $1.15(1.11-1.18)$ & 3.39 & $1.13(1.09-1.18)$ & 9.75 & $1.24(1.21-1.27)$ \\
\hline Yes $(n=15719)$ & 7.22 & $1.03(0.88-1.22)$ & 4.68 & $1.11(0.90-1.36)$ & 32.14 & $1.18(1.09-1.28)$ \\
\hline$P$ for interaction & & 0.213 & & 0.682 & & 0.702 \\
\hline \multicolumn{7}{|l|}{ Income lower $20 \%$} \\
\hline No $(n=477241)$ & 5.08 & $1.08(1.05-1.12)$ & 3.22 & $1.10(1.05-1.14)$ & 8.82 & $1.21(1.18-1.24)$ \\
\hline Yes $(n=146996)$ & 5.83 & $1.07(1.01-1.13)$ & 3.57 & $1.07(1.00-1.15)$ & 10.57 & $1.12(1.08-1.17)$ \\
\hline$P$ for interaction & & 0.759 & & 0.618 & & 0.001 \\
\hline
\end{tabular}

Adjusted for age, sex, body mass index, alcohol drinking, smoking, regular exercise, presence of hypertension, dyslipidemia, chronic kidney disease, and lower 20\% income, duration of diabetes over 5 years, the number of classes of oral anti-diabetic medication taken in the 12 months prior to baseline, presence of prescription history of insulin, and mean of fasting glucose

ICD-10 codes and patient prescription histories in addition to fasting glucose level. Second, possible selection bias due to extracting patients based on the number of health check-ups is one of the limitations. To overcome it, we conducted various subgroup analyses. Finally, classification of T1DM based on the presence of ICD-10 E10 with at least one prescription of insulin might not be accurate. Because ICD-10 code is based on claims data, but autoantibody, insulin, or c-peptide level was not measured, the prevalence of T1DM could be overestimated. However, we performed subgroup analysis after stratifying the subjects according to subtype of diabetes. There was a significance in all-cause mortality in T1DM. The absence of significance in stroke and MI was thought to be related to the small number of population. 
Table 4 Subgroup analysis according to the characteristics of diabetes in quartile 4 versus fasting glucose variability of quartiles 1-3

\begin{tabular}{|c|c|c|c|c|c|c|}
\hline & \multicolumn{2}{|l|}{ Stroke } & \multicolumn{2}{|c|}{ Myocardial infarction } & \multicolumn{2}{|c|}{ All-cause mortality } \\
\hline & IR per 1000 & $\mathrm{HR}(95 \% \mathrm{CI})$ & IR per 1000 & $\mathrm{HR}(95 \% \mathrm{Cl})$ & IR per 1000 & $\mathrm{HR}(95 \% \mathrm{Cl})$ \\
\hline \multicolumn{7}{|l|}{ Duration of diabetes ${ }^{\mathrm{a}}$} \\
\hline$<5$ years $(n=412310)$ & 4.02 & $1.01(0.97-1.06)$ & 2.63 & $1.03(0.98-1.08)$ & 7.41 & $1.16(1.12-1.19)$ \\
\hline$\geq 5$ years $(n=211927)$ & 7.74 & $1.17(1.12-1.22)$ & 4.66 & $1.17(1.11-1.24)$ & 12.87 & $1.22(1.18-1.26)$ \\
\hline$P$ for interaction & & $<0.001$ & & 0.001 & & 0.011 \\
\hline \multicolumn{7}{|l|}{ Baseline fasting glucose $\mathrm{e}^{\mathrm{a}}$} \\
\hline$<126 \mathrm{mg} / \mathrm{dL}(\mathrm{n}=188779)$ & 6.30 & $1.21(1.15-1.27)$ & 3.94 & $1.16(1.09-1.23)$ & 11.64 & $1.17(1.13-1.21)$ \\
\hline$\geq 126 \mathrm{mg} / \mathrm{dL}(\mathrm{n}=435458)$ & 4.81 & $0.95(0.92-0.99)$ & 3.03 & $1.01(0.96-1.06)$ & 8.20 & $1.11(1.08-1.14)$ \\
\hline$P$ for interaction & & $<0.001$ & & $<0.001$ & & $<0.001$ \\
\hline \multicolumn{7}{|l|}{ Subtype of diabetes ${ }^{a}$} \\
\hline T2DM $(n=608626)$ & 5.02 & $1.14(1.11-1.17)$ & 3.26 & $1.14(1.10-1.19)$ & 9.70 & $1.22(1.19-1.25)$ \\
\hline $\operatorname{T1DM}(n=15611)$ & 13.49 & $1.11(0.99-1.24)$ & 8.01 & $0.96(0.84-1.11)$ & 26.23 & $1.25(1.15-1.35)$ \\
\hline$P$ for interaction & & 0.267 & & 0.065 & & 0.186 \\
\hline \multicolumn{7}{|l|}{ Metformin ${ }^{b}$} \\
\hline No $(n=327239)$ & 4.05 & $1.17(1.12-1.22)$ & 2.48 & $1.18(1.12-1.25)$ & 8.59 & $1.30(1.26-1.34)$ \\
\hline Yes $(n=296998)$ & 7.22 & $1.18(1.13-1.22)$ & 4.72 & $1.16(1.11-1.22)$ & 12.80 & $1.25(1.22-1.29)$ \\
\hline$P$ for interaction & & 0.622 & & 0.976 & & 0.150 \\
\hline \multicolumn{7}{|l|}{ Sulfonylurea ${ }^{b}$} \\
\hline No $(n=323998)$ & 3.56 & $1.19(1.13-1.24)$ & 2.48 & $1.18(1.12-1.25)$ & 7.42 & $1.30(1.26-1.34)$ \\
\hline Yes $(n=300239)$ & 7.72 & $1.17(1.13-1.21)$ & 4.72 & $1.16(1.11-1.22)$ & 14.16 & $1.26(1.23-1.30)$ \\
\hline$P$ for interaction & & 0.858 & & 0.976 & & 0.380 \\
\hline \multicolumn{7}{|l|}{ Meglitinide ${ }^{b}$} \\
\hline No $(n=608306)$ & 5.19 & $1.17(1.13-1.20)$ & 3.34 & $1.16(1.12-1.20)$ & 10.02 & $1.27(1.25-1.30)$ \\
\hline Yes $(n=15931)$ & 10.02 & $1.28(1.11-1.48)$ & 6.51 & $1.37(1.15-1.64)$ & 20.14 & $1.37(1.24-1.52)$ \\
\hline$P$ for interaction & & 0.139 & & 0.056 & & 0.080 \\
\hline \multicolumn{7}{|l|}{ Thiazolidinedione $e^{b}$} \\
\hline No $(n=573541)$ & 5.21 & $1.17(1.14-1.21)$ & 3.37 & $1.17(1.13-1.22)$ & 10.17 & $1.28(1.25-1.31)$ \\
\hline Yes $(n=50696)$ & 6.44 & $1.17(1.06-1.29)$ & 3.97 & $1.13(0.99-1.28)$ & 11.37 & $1.25(1.16-1.34)$ \\
\hline$P$ for interaction & & 0.969 & & 0.561 & & 0.526 \\
\hline \multicolumn{7}{|l|}{ DPP-4 inhibitor ${ }^{b}$} \\
\hline No $(n=576404)$ & 5.25 & $1.17(1.13-1.20)$ & 3.37 & $1.17(1.13-1.21)$ & 10.23 & $1.27(1.25-1.30)$ \\
\hline Yes $(n=47833)$ & 6.06 & $1.21(1.09-1.35)$ & 4.06 & $1.18(1.03-1.35)$ & 10.63 & $1.35(1.24-1.46)$ \\
\hline$P$ for interaction & & 0.287 & & 0.835 & & 0.079 \\
\hline \multicolumn{7}{|l|}{ a-Glucosidase inhibitor ${ }^{b}$} \\
\hline No $(n=543357)$ & 4.70 & $1.15(1.12-1.19)$ & 3.09 & $1.15(1.10-1.20)$ & 9.29 & $1.28(1.25-1.31)$ \\
\hline Yes $(n=80880)$ & 9.92 & $1.23(1.16-1.32)$ & 5.94 & $1.24(1.14-1.34)$ & 17.62 & $1.25(1.19-1.31)$ \\
\hline$P$ for interaction & & 0.053 & & 0.157 & & 0.519 \\
\hline \multicolumn{7}{|l|}{ Insulin ${ }^{b}$} \\
\hline No $(n=580262)$ & 4.75 & $1.15(1.11-1.18)$ & 3.05 & $1.14(1.10-1.19)$ & 9.02 & $1.24(1.22-1.27)$ \\
\hline Yes $(n=43975)$ & 11.68 & $1.11(1.03-1.19)$ & 7.68 & $1.08(0.99-1.18)$ & 24.31 & $1.19(1.13-1.25)$ \\
\hline$P$ for interaction & & 0.874 & & 0.568 & & 0.492 \\
\hline
\end{tabular}

a Adjusted for age, sex, body mass index, alcohol drinking, smoking, regular exercise, presence of hypertension, dyslipidemia, chronic kidney disease, and lower $20 \%$ income, duration of diabetes over 5 years, the number of classes of oral anti-diabetic medication taken in the 12 months prior to baseline, presence of prescription history of insulin, and mean of fasting glucose

b Adjusted for age, sex, body mass index, alcohol drinking, smoking, regular exercise, presence of hypertension, dyslipidemia, chronic kidney disease, and lower $20 \%$ income, duration of diabetes over 5 years, and mean of fasting glucose 

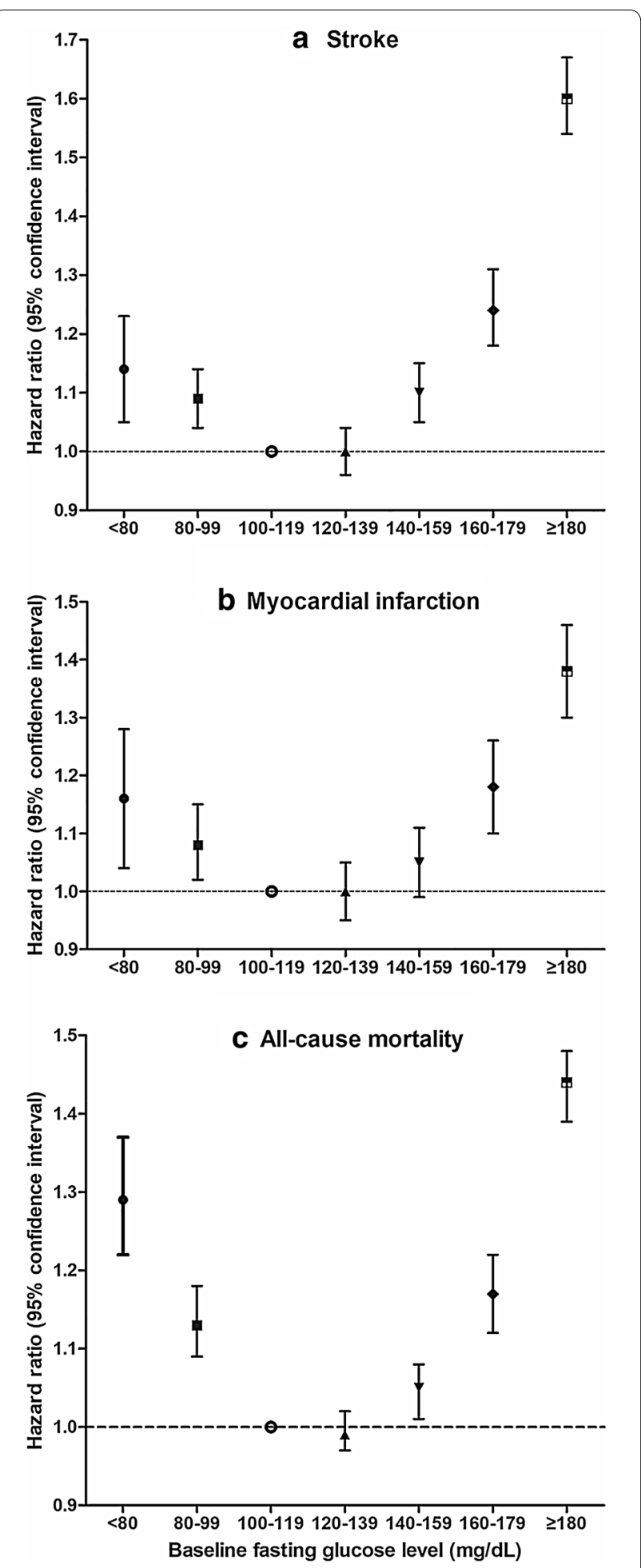

Fig. 4 Hazard ratios (HRs) of (a) stroke, (b) myocardial infarction, and (c) all-cause mortality according to baseline fasting glucose level

\section{Conclusion}

This nationwide population-based study with longterm follow-up showed that GV had a dose-response relationship with the risk of stroke, MI, and all-cause mortality in diabetes, especially in the elderly and those with a longer duration of diabetes and lower FG levels. This important health issue will play a role in reducing future development of CVD and death attributed to the increasing population of diabetes.

\section{Supplementary information}

Supplementary information accompanies this paper at https://doi. org/10.1186/s12933-020-01134-0.

Additional file 1: Table S1. Hazard ratios (HRs) and 95\% confidence intervals (Cls) for the incidence of stroke, myocardial infarction, and all-cause mortality by quartiles of fasting glucose variability, assessed by standard deviation, coefficient of variation, and average real variability. Table S2. Hazard ratios (HRs) and 95\% confidence intervals (Cls) for the incidence of stroke, myocardial infarction, and all-cause mortality by deciles of fasting glucose variability. Table S3. Hazard ratios (HRs) and 95\% confidence intervals (Cls) for the incidence of stroke, myocardial infarction, and allcause mortality according to baseline fasting glucose level. Table S4. Hazard ratios (HRs) and 95\% confidence intervals (Cls) according to baseline fasting glucose level and antidiabetic medication (ADM).

\section{Abbreviations}

ARV: Average real variability; BMI: Body mass index; BP: Blood pressure; Cl: Confidence interval; CKD: Chronic kidney disease; CV: Coefficient of variation; CVD: Cardiovascular disease; DPP-4 inhibitors: Inhibitors of dipeptidyl peptidase 4; eGFR: Estimated glomerular filtration rate; FG: Fasting glucose; GV: Glucose variability; HR: Hazard ratio; ICD-10: International Classification of Diseases, tenth revision; LDL-C: low-density lipoprotein cholesterol; Ml: Myocardial infarction; NHIC: National Health Insurance System; SD: Standard deviation; T1DM: Type 1 diabetes; T2DM: Type 2 diabetes; VIM: Variability independent of the mean.

\section{Acknowledgements}

Not applicable.

\section{Authors' contributions}

Conception and design: DYL, KH and NHK (Nan Hee Kim); Analysis and interpretation of the data: DYL, SP, JAS, NHK (Nam Hoon Kim), HJY and NHK (Nan Hee Kim); Drafting of the article: DYL and JHY; Critical revision for important intellectual content: SGK, KMC and SHB; Final approval of the article: YGP and NHK (Nan Hee Kim); Statistical expertise, Collection and assembly of data: $\mathrm{KH}$. SP and YGP; Obtaining of funding: DYL and NHK (Nan Hee Kim); Administrative, technical, or logistic support: YGP. All authors read and approved the final manuscript

\section{Funding}

This study was supported by the Bio \& Medical Technology Development Program of the National Research Foundation (NRF) funded by the Korean government (MSIT) (NRF-2019M3E5D3073102 and NRF-2019R1H1A2039682) and supported by Korea University Ansan Hospital Grant (O1903661). However, funders did not participate in the study's design or reporting. 


\section{Availability of data and materials}

The data that support the findings of this study are available from the National Health Insurance Corporation but restrictions apply to the availability of these data, which were used under license for the current study, and so are not publicly available. Data are however available from the authors upon reasonable request and with permission of the National Health Insurance Corporation.

\section{Ethics approval and consent to participate}

Not applicable.

\section{Consent for publication}

Not applicable.

\section{Competing interests}

The authors declare that they have no competing interests.

\section{Author details}

${ }^{1}$ Division of Endocrinology and Metabolism, Department of Internal Medicine, Korea University College of Medicine, Seoul, Republic of Korea. ${ }^{2}$ Department of Biostatics, College of Medicine, The Catholic University of Korea, 222, Banpo-daero, Seocho-gu, Seoul 06591, Republic of Korea. ${ }^{3}$ Division of Endocrinology and Metabolism, Department of Internal Medicine, Korea University Ansan Hospital, Korea University College of Medicine, Danwon-gu, Ansan-si, Gyeonggi-do 15355, Republic of Korea.

Received: 12 June 2020 Accepted: 18 September 2020 Published online: 22 September 2020

\section{References}

1. 6 Glycemic Targets: standards of medical care in diabetes-2018. Diabetes Care. 2018;41:S55-S64

2. Wan EYF, Yu EYT, Fung CSC, Chin WY, Fong DYT, Chan AKC, et al. Relation between $\mathrm{HbA} 1 \mathrm{c}$ and incident cardiovascular disease over a period of 6 years in the Hong Kong population. Diabetes Metab. 2018;44:415-23.

3. Arem H, Moore SC, Patel A, Hartge P, de Gonzalez BA, Visvanathan K, et al. Leisure time physical activity and mortality: a detailed pooled analysis of the dose-response relationship. JAMA Intern Med. 2015;175:959-67.

4. Škrha J, Šoupal J, Škrha J Jr, Prázný M. Glucose variability, HbA1c and microvascular complications. Rev Endocrine Metab Disorders. 2016;17:103-10.

5. Siegelaar SE, Holleman F, Hoekstra JBL, DeVries JH. Glucose variability; does it matter? Endocr Rev. 2010;31:171-82.

6. Sun B, He F, Gao Y, Zhou J, Sun L, Liu R, et al. Prognostic impact of visitto-visit glycemic variability on the risks of major adverse cardiovascular outcomes and hypoglycemia in patients with different glycemic control and type 2 diabetes. Endocrine. 2019;64:536-43.

7. Zhou JJ, Schwenke DC, Bahn G, Reaven P. Glycemic variation and cardiovascular risk in the Veterans Affairs Diabetes trial. Diabetes Care. 2018:41:2187-94.

8. Ferreira L, Moniz AC, Carneiro AS, Miranda AS, Fangueiro C, Fernandes D, et al. The impact of glycemic variability on length of stay and mortality in diabetic patients admitted with community-acquired pneumonia or chronic obstructive pulmonary disease. Diabetes Metab Syndr. 2019;13:149-53.

9. Yokota S, Tanaka H, Mochizuki Y, Soga F, Yamashita K, Tanaka Y, et al. Association of glycemic variability with left ventricular diastolic function in type 2 diabetes mellitus. Cardiovasc Diabetol. 2019;18:166.

10. Lu J, Ma X, Zhang L, Mo Y, Lu W, Zhu W, et al. Glycemic variability modifies the relationship between time in range and hemoglobin A1c estimated from continuous glucose monitoring: a preliminary study. Diabetes Res Clin Pract. 2020;161:108032.

11. Besch G, Pili-Floury S, Morel C, Gilard M, Flicoteaux G, du Mont SL, et al. Impact of post-procedural glycemic variability on cardiovascular morbidity and mortality after transcatheter aortic valve implantation: a post hoc cohort analysis. Cardiovasc Diabetol. 2019;18:27.

12. Zhang Y, Dai J, Han X, Zhao Y, Zhang H, Liu X, et al. Glycemic variability indices determined by self-monitoring of blood glucose are associated with $\beta$-cell function in Chinese patients with type 2 diabetes. Diabetes Res Clin Pract. 2020;164:108152.
13. Takahashi H, Iwahashi N, Kirigaya J, Kataoka S, Minamimoto Y, Gohbara $M$, et al. Glycemic variability determined with a continuous glucose monitoring system can predict prognosis after acute coronary syndrome. Cardiovasc Diabetol. 2018;17:116.

14. Cardoso CRL, Leite NC, Moram CBM, Salles GF. Long-term visit-to-visit glycemic variability as predictor of micro- and macrovascular complications in patients with type 2 diabetes: the Rio de Janeiro Type 2 Diabetes Cohort Study. Cardiovasc Diabetol. 2018;17:33.

15. Hirakawa $Y$, Arima H, Zoungas S, Ninomiya T, Cooper M, Hamet $P$, et al. Impact of visit-to-visit glycemic variability on the risks of macrovascular and microvascular events and all-cause mortality in type 2 diabetes: the ADVANCE trial. Diabetes Care. 2014;37:2359-65.

16. Tang X, Li S, Wang Y, Wang M, Yin Q, Mu P, et al. Glycemic variability evaluated by continuous glucose monitoring system is associated with the 10-y cardiovascular risk of diabetic patients with well-controlled $\mathrm{HbA} 1 \mathrm{c}$. Clin Chim Acta. 2016;461:146-50.

17. Muggeo M, Zoppini G, Bonora E, Brun E, Bonadonna RC, Moghetti P, et al. Fasting plasma glucose variability predicts 10-year survival of type 2 diabetic patients: the Verona Diabetes Study. Diabetes Care. 2000;23:45-50.

18. Zoppini G, Verlato G, Targher G, Bonora E, Trombetta M, Muggeo M. Variability of body weight, pulse pressure and glycaemia strongly predict total mortality in elderly type 2 diabetic patients. The Verona Diabetes Study. Diabetes Metab Res Rev. 2008;24:624-8.

19. Rizvi SI, Maurya PK. Markers of oxidative stress in erythrocytes during aging in humans. Ann NY Acad Sci. 2007;1100:373-82.

20. Xu D, Fang H, Xu W, Yan Y, Liu Y, Yao B. Fasting plasma glucose variability and all-cause mortality among type 2 diabetes patients: a dynamic cohort study in Shanghai, China. Sci Rep. 2016;6:39633.

21. Muggeo M, Verlato G, Bonora E, Zoppini G, Corbellini M, de Marco R. Long-term instability of fasting plasma glucose, a novel predictor of cardiovascular mortality in elderly patients with non-insulindependent diabetes mellitus: the Verona Diabetes Study. Circulation. 1997:96:1750-4

22. Song SO, Jung CH, Song YD, Park CY, Kwon HS, Cha BS, et al. Background and data configuration process of a nationwide populationbased study using the korean national health insurance system. Diabetes Metab J. 2014;38:395-403.

23. Lee $\mathrm{YH}, \mathrm{Han} \mathrm{K}$, Ko SH, Ko KS, Lee KU. Data analytic process of a nationwide population-based study using National Health Information Database established by National Health Insurance Service. Diabetes Metab J. 2016;40:79-82.

24. Rothwell PM, Howard SC, Dolan E, O'Brien E, Dobson JE, Dahlof B, et al. Prognostic significance of visit-to-visit variability, maximum systolic blood pressure, and episodic hypertension. Lancet. 2010;375:895-905.

25. Oh JY, Yang YJ, Kim BS, Kang JH. Validity and reliability of Korean version of International Physical Activity Questionnaire (IPAQ) short form. J Korean Acad Fam Med. 2007;28:532-41.

26. Levey AS, Coresh J, Greene T, Stevens LA, Zhang YL, Hendriksen S, et al. Using standardized serum creatinine values in the modification of diet in renal disease study equation for estimating glomerular filtration rate. Ann Intern Med. 2006;145:247-54.

27. Group KDIGOCW. KDIGO 2012 clinical practice guideline for the evaluation and management of chronic kidney disease: Chapter 1: definition and classification of CKD. Kidney Int Suppl. 2013;2013(3):19-62.

28. Zhang XG, Zhang YQ, Zhao DK, Wu JX, Zhao J, Jiao XM, et al. Relationship between blood glucose fluctuation and macrovascular endothelial dysfunction in type 2 diabetic patients with coronary heart disease. Eur Rev Med Pharm Sci. 2014;18:3593-600.

29. Ceriello A, Esposito K, Piconi L, Ihnat MA, Thorpe JE, Testa R, et al. Oscillating glucose is more deleterious to endothelial function and oxidative stress than mean glucose in normal and type 2 diabetic patients. Diabetes. 2008;57:1349-54.

30. Salisbury D, Bronas U. Reactive oxygen and nitrogen species: impact on endothelial dysfunction. Nurs Res. 2015;64:53-66.

31. El-Osta A, Brasacchio D, Yao D, Pocai A, Jones PL, Roeder RG, et al. Transient high glucose causes persistent epigenetic changes and altered gene expression during subsequent normoglycemia. J Exp Med. 2008:205:2409-17.

32. Okada K, Hibi K, Gohbara M, Kataoka S, Takano K, Akiyama E, et al. Association between blood glucose variability and coronary plaque 
instability in patients with acute coronary syndromes. Cardiovasc Diabetol. 2015;14:111.

33. Yamazaki M, Hasegawa G, Majima S, Mitsuhashi K, Fukuda T, I wase H, et al. Effect of repaglinide versus glimepiride on daily blood glucose variability and changes in blood inflammatory and oxidative stress markers. Diabetol Metab Syndr. 2014;6:54.

34. Suh S, Kim H, Dang-Vu TT, Joo E, Shin C. Cortical thinning and altered cortico-cortical structural covariance of the default mode network in patients with persistent insomnia symptoms. Sleep. 2016:39:161-71.

35. Heinemann L, Fleming GA, Petrie JR, Holl RW, Bergenstal RM, Peters AL. Insulin pump risks and benefits: a clinical appraisal of pump safety standards, adverse event reporting, and research needs. Diabetes Care. 2015;38:716-22.

36. Vora J, Cariou B, Evans M, Gross JL, Harris S, Landstedt-Hallin L, et al. Clinical use of insulin degludec. Diabetes Res Clin Pract. 2015;109:19-31.

37. Inzucchi SE, Umpierrez G, DiGenio A, Zhou R, Kovatchev B. How well do glucose variability measures predict patient glycaemic outcomes during treatment intensification in type 2 diabetes? Diabetes Res Clin Pract. 2015:108:179-86.

38. Hansen TW, Thijs L, Li Y, Boggia J, Kikuya M, Björklund-Bodegård K, et al. Prognostic value of reading-to-reading blood pressure variability over 24 hours in 8938 subjects from 11 populations. Hypertension. 2010;55:1049-57.

39. Mena L, Pintos S, Queipo NV, Aizpúrua JA, Maestre G, Sulbarán T. A reliable index for the prognostic significance of blood pressure variability. J Hypertens. 2005;23:505-11.

40. Lee HJ, Choi EK, Han KD, Lee E, Moon I, Lee SR, et al. Bodyweight fluctuation is associated with increased risk of incident atrial fibrillation. Heart Rhythm. 2020;17:365-71.

41. Yano Y. Visit-to-visit blood pressure variability-what is the current challenge? Am J Hypertens. 2017;30:112-4.

42. Bangalore S, Breazna A, DeMicco DA, Wun CC, Messerli FH. Visit-to-visit low-density lipoprotein cholesterol variability and risk of cardiovascular outcomes: insights from the TNT trial. J Am Coll Cardiol. 2015;65:1539-48,

43. Dolan E, O'Brien E. Blood pressure variability: clarity for clinical practice. Hypertension. 2010;56:179-81.

\section{Publisher's Note}

Springer Nature remains neutral with regard to jurisdictional claims in published maps and institutional affiliations.
Ready to submit your research? Choose BMC and benefit from:

- fast, convenient online submission

- thorough peer review by experienced researchers in your field

- rapid publication on acceptance

- support for research data, including large and complex data types

- gold Open Access which fosters wider collaboration and increased citations

- maximum visibility for your research: over $100 \mathrm{M}$ website views per year

At BMC, research is always in progress.

Learn more biomedcentral.com/submissions 